\title{
A recently recognized ambident reactivity of 2,3-diamino-isoquinolinium salts
}

\author{
Zsuzsanna Riedl, László Filák, Orsolya Egyed, and György Hajós* \\ Chemical Research Center of the Hungarian Academy of Sciences, H-1025 Budapest, \\ Pusztaszeri út 59, Hungary \\ E-mail: ghajos@chemres.hu
}

\section{Dedicated to Professor Henk van der Plas on the occasion of his $80^{\text {th }}$ birthday}

\begin{abstract}
Reinvestigation of an old experimental finding - the formation of linearly fused tetrazoloisoquinolines from 2,3-diamino-isoquinolinium salts, by using ${ }^{15} \mathrm{~N}$-labeling and ${ }^{15} \mathrm{~N}-\mathrm{NMR}$ spectroscopy, revealed that the ring closure pathway - unlike a recently observed cyclization of the same diamino salt - does not proceed via a rearrangement route. By comparison of this reaction with the entirely different reactivities of other related 1,2-diamino-azinium salts, a general mechanism is suggested, revealing an ambident reactivity of these diamino compounds.
\end{abstract}

Keywords: Ring closure, azide-tetrazole equilibrium, ambident reactivity, deamination reaction, ${ }^{15} \mathrm{~N}$-labeling, ${ }^{15} \mathrm{~N}-\mathrm{NMR}$ spectroscopy

\section{Introduction}

Recently we have reported ${ }^{1}$ that the reaction of the 2,3-diamino-isoquinolinium salt (1) with aldehydes in the presence of a base and ethanol results in a Dimroth rearrangement leading to the formation of 3-isoquinolylhydrazones (Scheme 1). The transformation was rationalized by a nucleophilic addition of an ethoxide anion leading to the first intermediate, a, followed by an electrocyclic ring opening to the species $\mathbf{b}$ which, by turning of the $\mathrm{C} 3-\mathrm{C} 4$ bond according to the arrow leads to $\mathbf{c}$. This conformer can again participate in ring closure to $\mathbf{d}-$ a reverse process of the ring opening $\mathbf{a} \rightarrow \mathbf{b}$ - and, finally, elimination of ethanol affords formation of the hydrazone product. The rearrangement has been verified by ${ }^{15} \mathrm{~N}$-isotope labeling. Both the $C$-aminonitrogen atom (printed in green) and the $N$-amino-nitrogen atom (in blue) have been labeled with ${ }^{15} \mathrm{~N}$, and the different locations of these nitrogen atoms in the final product compared to those in the starting compound, unambiguously supported the fact of rearrangement. 


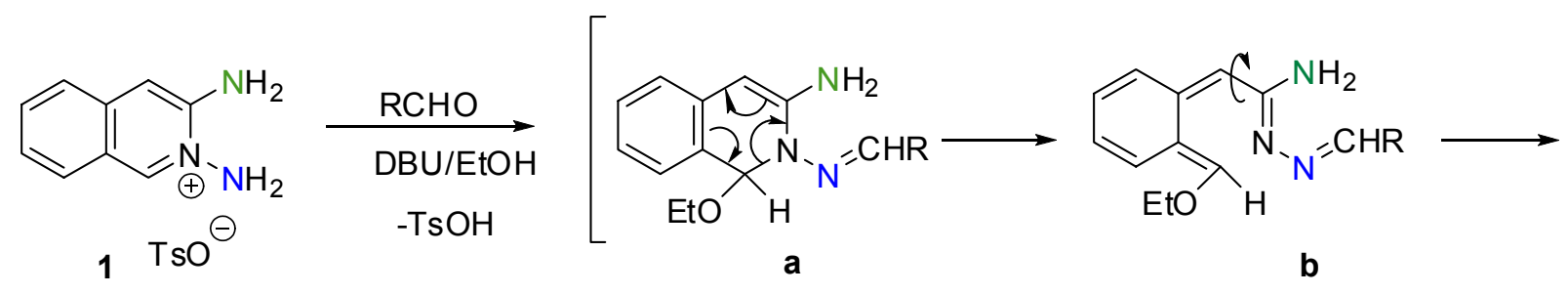

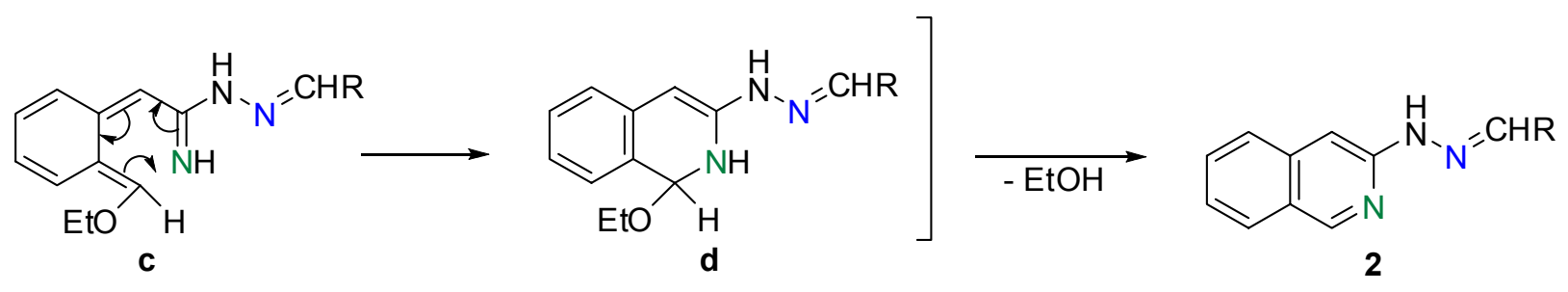

\section{Scheme 1}

By recognition of this rearrangement reaction, an old experimental finding published three decades ago ${ }^{2}$ became of particular interest. As shown in Scheme $2,{ }^{2}$ we described that the 2,3diamino-4-substituted isoquinolinium salts 3 are convenient starting compounds for the synthesis of tetrazolo[1,5- $b$ ]isoquinolines $4^{3}$ carried out by treatment of 3 with nitrous acid. Most surprisingly, this approach was successfully applied only for 2,3-diamino-isoquinolinium salts, whereas no such transformation could be carried out with 1,2-diaminopyridinium salts or its benzologues other than $\mathbf{3}$. As the outstanding reactivity of $\mathbf{3}$ might have been due a rearrangement similar to $\mathbf{a} \rightarrow \mathbf{d}$ (shown in Scheme 1), a reinvestigation of the cyclization $\mathbf{3} \rightarrow \mathbf{4}$ has been made, and arguments for or against the rearrangement possibility have been considered.

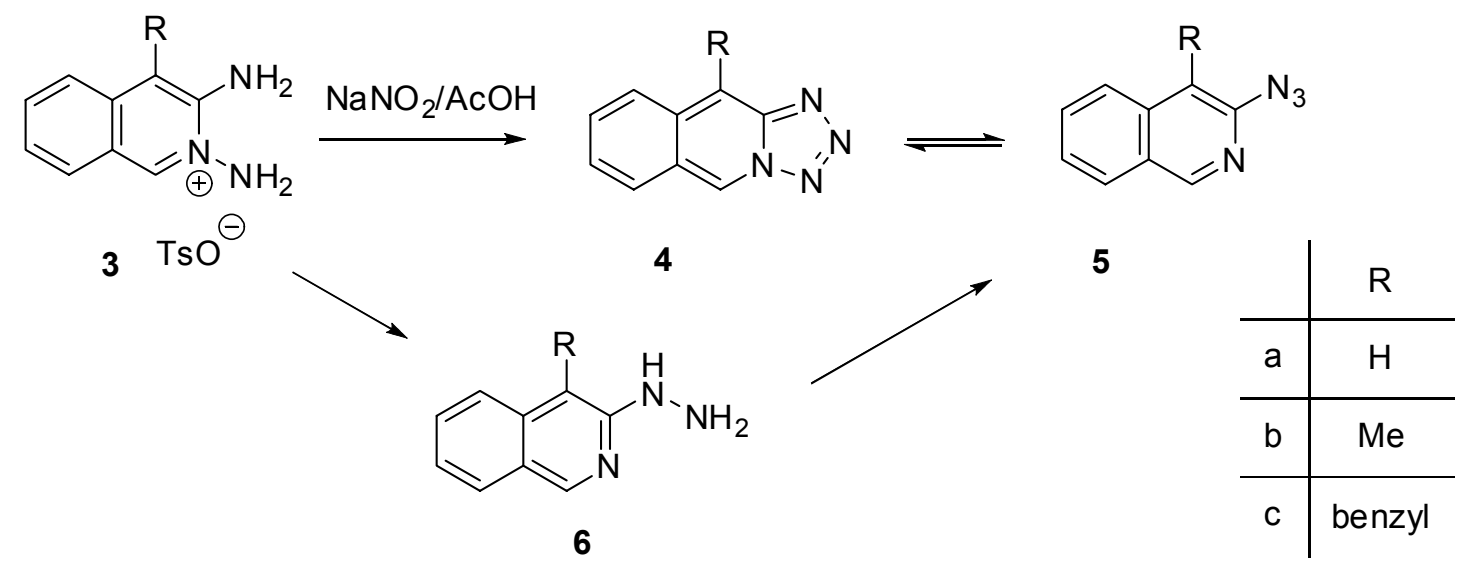

\section{Scheme 2}




\section{Results and Discussion}

Following the above considerations, the experimental finding of the rearrangement of $\mathbf{1}$ suggested that the cyclization $\mathbf{3} \rightarrow \mathbf{4}$ - similar to the events depicted in Scheme 1 - may also proceed via a rearrangement. This possibility is demonstrated in Scheme 2: if the salt 3 participates in a Dimroth rearrangement, the 3-hydrazino-isoquinoline $\mathbf{6}$ would be formed, and the treatment of this compound with nitrous acid would afford an azide $\mathbf{5}$ in equilibrium with the tetrazole $4{ }^{4}$ In order to clarify the locations of the particular nitrogen atoms in the unsubstituted tetrazole 4a deriving from these atoms in the starting compound $\mathbf{3 a}$, three types of isotope labeling were applied. The two amino-nitrogen atoms of $\mathbf{3 a}$ were separately labeled by the ${ }^{15} \mathrm{~N}$ isotope (i.e. two isotopomers of $\mathbf{3 a}$ * were synthesized) and, furthermore, the unlabelled $\mathbf{3}$ was reacted with ${ }^{15} \mathrm{~N}$-labeled nitrous acid. The three labeling possibilities are shown in Scheme 3: The $C$-amino-nitrogen atom is printed in green, the $N$-amino-nitrogen atom in blue, and the nitrogen atom coming from nitrous acid is shown in red.

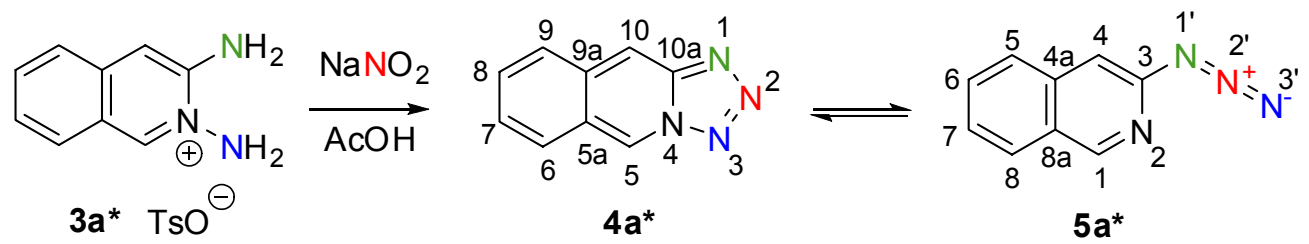

\section{Scheme 3}

The nitrogen resonances $\left({ }^{15} \mathrm{~N}\right)$ were determined for the non-labeled compound in natural abundance using ${ }^{1} \mathrm{H}_{-}{ }^{15} \mathrm{~N}$ HMQC measurements. The observed ${ }^{15} \mathrm{~N}$ shifts - similar to ${ }^{1} \mathrm{H}$ - and ${ }^{13} \mathrm{C}$ chemical shifts - proved the co-existence of both tetrazole and azide ring - chain tautomers. The complete assignment of chemical shifts appearing in the ${ }^{1} \mathrm{H}-,{ }^{13} \mathrm{C}$-, and ${ }^{15} \mathrm{~N}-\mathrm{NMR}$ spectra indicative of the different structures, i.e., tetrazole-azide $(\mathrm{R}=\mathrm{H}, \mathbf{4 a}$ and $\mathbf{5 a})$, are summarized in Table 1.

After assignment of the particular nitrogen shifts, direct $1 \mathrm{D}-{ }^{15} \mathrm{~N}$-measurements with the labeled compounds have been carried out in order to clarify the position of the labeled nitrogen atoms. ${ }^{6}$ In accord with the presence of the azide-tetrazole equilibrium mixture, only two ${ }^{15} \mathrm{~N}$ shifts were detected in each case. The ${ }^{15} \mathrm{~N}-\mathrm{NMR}$ assignments clearly showed that all nitrogen atoms (the green and blue ones) remained in their original positions, and the nitrogen atom provided by the reagent nitrous acid (in red) became position 2 in the tricyclic tetrazole ring. Thus, the assumed rearrangement of $\mathbf{3}$ in the course of the cyclization reaction pathway to $\mathbf{4}$ can definitely be ruled out. 
Table 1. ${ }^{1} \mathrm{H}$-, ${ }^{13} \mathrm{C}$-, and ${ }^{15} \mathrm{~N}$-NMR chemical shifts of tetrazole (4a) and azide (5a) measured in DMSO- $d_{6}$ solution at $25{ }^{\circ} \mathrm{C}$

\begin{tabular}{|c|c|c|c|c|c|c|c|c|c|c|c|}
\hline \multicolumn{6}{|c|}{ Tetrazole (4a) } & \multicolumn{6}{|c|}{ Azide (5a) } \\
\hline & \multicolumn{2}{|l|}{$\delta(\mathrm{ppm})$} & \multicolumn{2}{|l|}{$\delta(\mathrm{ppm})$} & \multirow{2}{*}{$\delta(\mathrm{ppm})$} & \multicolumn{2}{|c|}{$\delta(\mathrm{ppm})$} & \multicolumn{3}{|c|}{$\delta(\mathrm{ppm})$} & \multirow[t]{2}{*}{$\delta(\mathrm{ppm})$} \\
\hline & & & & $\mathrm{N}-1$ & & H-1 & 9.23 & C-1 & 153.3 & & \\
\hline & & & & $\mathrm{N}-2$ & +26.6 & & & & & $\mathrm{~N}-2$ & -89.4 \\
\hline & & & & N-3 & -35.7 & & & C-3 & 148.3 & & \\
\hline & & & & $\mathrm{N}-4$ & -125.5 & H-4 & 7.39 & C-4 & 108.5 & & \\
\hline \multirow[t]{2}{*}{ H-5 } & 10.30 & $\mathrm{C}-5$ & 126.0 & & & & & $C-4 a$ & 138.2 & & \\
\hline & & $C-5 a$ & 124.2 & & & $\mathrm{H}-5$ & 7.86 & $\mathrm{C}-5$ & 126.7 & & \\
\hline H-6 & 8.11 & C-6 & 128.0 & & & H-6 & 7.73 & C-6 & 132.0 & & \\
\hline $\mathrm{H}-7$ & 7.56 & C-7 & 128.4 & & & H-7 & 7.56 & C-7 & 128.7 & & \\
\hline H-8 & 7.64 & C-8 & 130.8 & & & H- 8 & 8.08 & C-8 & 127.3 & & \\
\hline \multirow[t]{2}{*}{ H-9 } & 8.07 & C-9 & 127.3 & & & & & $C-8 \mathrm{a}$ & 127.0 & & \\
\hline & & C-9a & 135.7 & & & & & & & $\mathrm{~N}-1$ ' & -274.0 \\
\hline \multirow[t]{2}{*}{$\mathrm{H}-10$} & 8.85 & $\mathrm{C}-10$ & 111.2 & & & & & & & $\mathrm{~N}-2$, & -136.0 \\
\hline & & $\mathrm{C}-10 \mathrm{a}$ & 146.9 & & & & & & & N-3, & -142.3 \\
\hline
\end{tabular}

Two related derivatives (i.e. $\mathbf{4 b}+\mathbf{5 b}$, and $\mathbf{4} \mathbf{c}+\mathbf{5} \mathbf{c}$ ) have also been investigated by ${ }^{1} \mathrm{H}-{ }^{13} \mathrm{C}$ NMR spectroscopy. The assignments of the chemical shifts are summarized in Tables 2 and 3 , respectively.

Table 2. ${ }^{1} \mathrm{H}$ - and ${ }^{13} \mathrm{C}$-NMR data for the tetrazole $\mathbf{4 b}$ and azide $\mathbf{5 b}$ in $\mathrm{CDCl}_{3}$ at $25{ }^{\circ} \mathrm{C}$

\begin{tabular}{|c|c|c|c|c|c|c|c|}
\hline \multicolumn{4}{|c|}{ Tetrazole (4b) } & \multicolumn{4}{|c|}{ Azide (5b) } \\
\hline & $\delta(\mathrm{ppm})$ & & $\delta(\mathrm{ppm})$ & & $\delta(\mathrm{ppm})$ & & $\delta(\mathrm{ppm})$ \\
\hline \multirow[t]{2}{*}{ H-5 } & 9.44 & C-5 & 121.0 & H-1 & 8.93 & C-1 & 150.2 \\
\hline & & $C-5 a$ & 124.4 & & & C-3 & 146.6 \\
\hline H-6 & 7.89 & C-6 & 127.0 & & & C-4 & 115.6 \\
\hline $\mathrm{H}-7$ & 7.52 & C-7 & 127.9 & & & C-4a & 137.4 \\
\hline $\mathrm{H}-8$ & 7.60 & $\mathrm{C}-8$ & 129.6 & H-5 & 7.87 & $\mathrm{C}-5$ & 123.2 \\
\hline \multirow[t]{4}{*}{ H-9 } & 8.06 & C-9 & 124.0 & H-6 & 7.68 & C-6 & 130.9 \\
\hline & & C-9a & 132.7 & $\mathrm{H}-7$ & 7.49 & $\mathrm{C}-7$ & 125.7 \\
\hline & & C-10 & 121.4 & H-8 & 7.91 & C-8 & 128.6 \\
\hline & & C-10a & 147.4 & & & $C-8 \mathrm{a}$ & 126.7 \\
\hline $\mathrm{CH}_{3}$ & 3.17 & $\mathrm{CH}_{3}$ & 13.6 & $\mathrm{CH}_{3}$ & 2.47 & $\mathrm{CH}_{3}$ & 12.0 \\
\hline
\end{tabular}


Table 3. ${ }^{1} \mathrm{H}$ - and ${ }^{13} \mathrm{C}$-NMR data for tetrazole $4 \mathbf{c}$ and azide $\mathbf{5 c}$ in DMSO- $d_{6}$ at $25{ }^{\circ} \mathrm{C}$

\begin{tabular}{|c|c|c|c|c|c|c|c|}
\hline \multicolumn{4}{|c|}{ Tetrazole (4c) } & \multicolumn{4}{|c|}{ Azide (5c) } \\
\hline \multicolumn{3}{|c|}{$\delta(\mathrm{ppm})$} & \multirow{2}{*}{$\frac{\delta(\mathrm{ppm})}{124.5}$} & \multicolumn{3}{|c|}{$\delta(\mathrm{ppm})$} & \multirow{2}{*}{$\frac{\delta(\mathrm{ppm}}{151.7}$} \\
\hline H-5 & 10.2 & C-5 & & $\mathrm{H}-1$ & 9.15 & C-1 & \\
\hline & & $C-5 a$ & 124.5 & & & C-3 & 146.4 \\
\hline H-6 & 8.12 & C-6 & 128.0 & & & C-4 & 120.0 \\
\hline $\mathrm{H}-7$ & 7.55 & C-7 & 127.8 & & & $C-4 a$ & 136.6 \\
\hline $\mathrm{H}-8$ & 7.65 & C-8 & 130.7 & $\mathrm{H}-5$ & 7.99 & $\mathrm{C}-5$ & 123.8 \\
\hline \multirow[t]{4}{*}{ H-9 } & 8.26 & C-9 & 124.2 & H-6 & 7.72 & C-6 & 132.1 \\
\hline & & C-9a & 132.4 & $\mathrm{H}-7$ & 7.64 & $\mathrm{C}-7$ & 130.8 \\
\hline & & $C-10$ & 122.6 & $\mathrm{H}-8$ & 8.10 & C-8 & 129.2 \\
\hline & & C-10a & 147.1 & & & C-8a & 126.5 \\
\hline \multirow[t]{2}{*}{$\mathrm{C}_{2}$} & 4.93 & $\underline{\mathrm{CH}_{2}}$ & 32.7 & $\mathrm{CH}_{2}$ & 4.29 & $\mathrm{CH}_{2}$ & 31.3 \\
\hline & & $\mathrm{C}-1$ & 139.5 & & & $\mathrm{C}-1$ & 140.0 \\
\hline $\mathrm{H} 2^{\prime}+\mathrm{H} 6^{\prime}$ & 7.31 & $\mathrm{C}^{\prime}+\mathrm{C} 6^{\prime}$ & 128.8 & $\mathrm{H} 2^{\prime}+\mathrm{H} 6^{\prime}$ & 7.31 & $\mathrm{C}^{\prime}+\mathrm{C}^{\prime}{ }^{\prime}$ & 128.8 \\
\hline $\mathrm{H} 3^{\prime}+\mathrm{H} 5^{\prime}$ & 7.19 & $\mathrm{C} 3^{\prime}+\mathrm{C} 5$ & 129.0 & $\mathrm{H} 3^{\prime}+\mathrm{H} 5^{\prime}$ & 7.19 & $\mathrm{C} 3^{\prime}+\mathrm{C} 5$ & 129.0 \\
\hline $\mathrm{H} 4$ & 7.11 & $\mathrm{C} 4$ & 126.9 & $\mathrm{H} 4$ & 7.11 & $\mathrm{C} 4$ & 126.9 \\
\hline
\end{tabular}

We repeated the experiments with the monocyclic 1,2-diaminopyridinium salt 7 and the related bicyclic diamino salts $\mathbf{1 0}$ and $\mathbf{1 2}$, and showed that these compounds behave totally differently under the reaction conditions used for the synthesis of $\mathbf{4}$. In these cases, a deamination (i.e., elimination of the $N$-amino moiety) takes place, and the parent amines 8 (together with a side product 9), 11, and 13, respectively, are formed (Scheme 4).

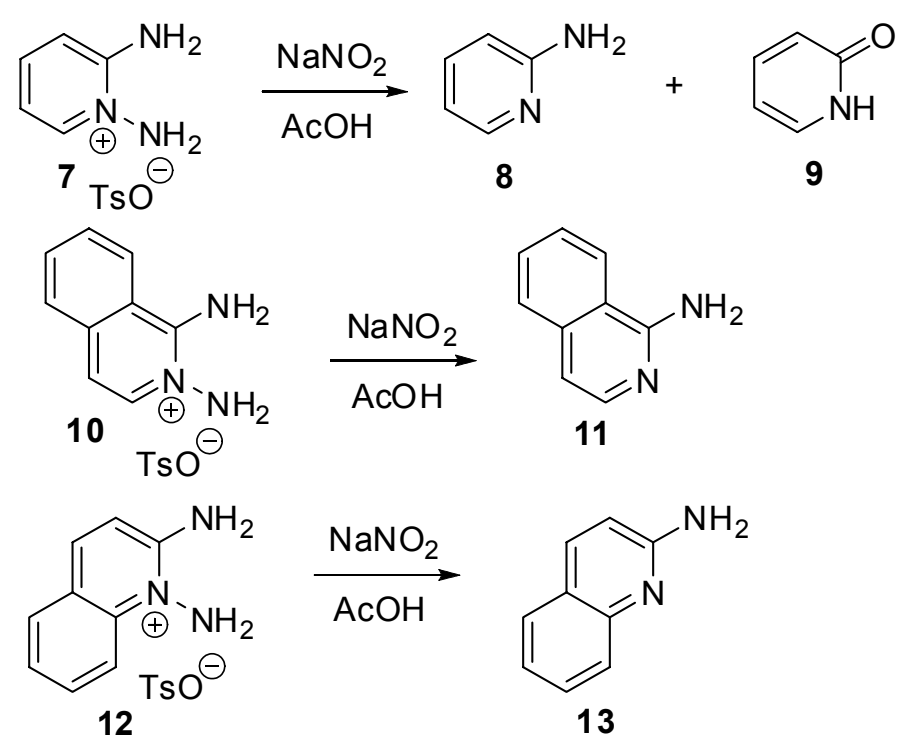

\section{Scheme 4}


This kind of $N$-amino-deamination has been documented in the literature ${ }^{7,8}$ and has been interpreted as an $N$-nitrosation followed by elimination of dinitrogen oxide.

Comparison of the transformations we have experienced, starting from $\mathbf{3}$, with those starting from 7, 10, and 12, suggested the following mechanistic picture (Figure 1).

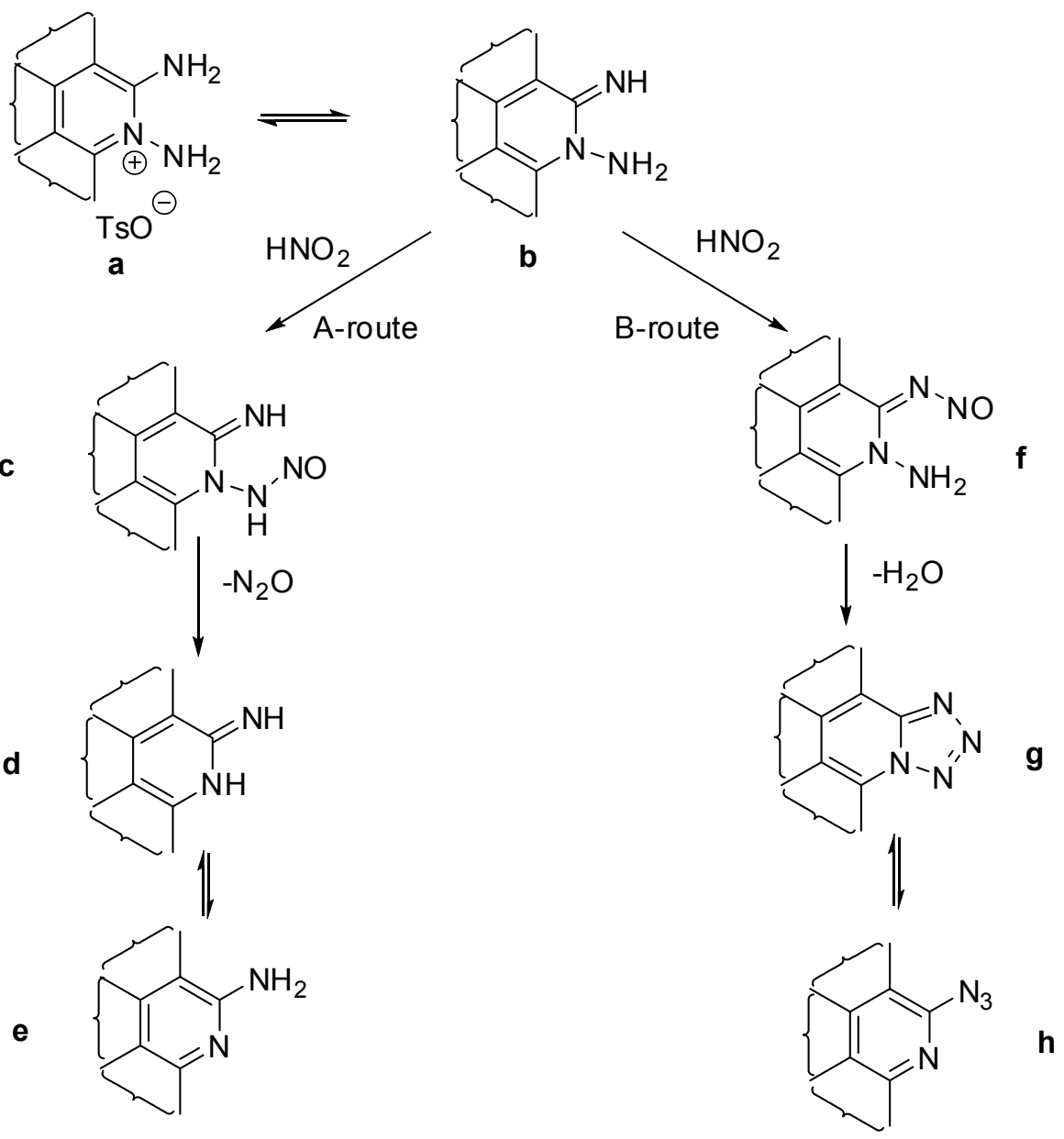

\section{Figure 1}

The difference in behavior of these two groups of diamino salts is obviously due to the different reactivity of the two amino-nitrogen atoms (i.e., the $\mathrm{C}$-amino- and $\mathrm{N}$-amino-ones). The reactive species in all these transformations is obviously a neutral imino-amino compound $\mathbf{b}$ formed in equilibrium by deprotonation of the salts a. In the imino-amino derivatives formed from 7, 10, and 12 they are the $N$-amino nitrogen atoms that react first with the nitrous acid (route A is realized) to form an $N$-nitroso species c which easily undergoes a dinitrogen oxide elimination to d, stabilized in the aromatic e form. In contrast to this pathway, treatment of the imino-amino compound $\mathbf{b}$ formed from $\mathbf{3}$ follows the B-route: here the imino-nitrogen atom reacts first to give a nitroso-imino intermediate f. In this intermediate the $N$-amino group acting 
as a nucleophile can attack the nitroso-nitrogen atom, and water-elimination can result in formation of the tetrazole $\mathbf{g}$ which is in equilibrium with the azide form $\mathbf{h}$.

The difference between the reactivities of the two types of amino-nitrogen atoms of the two groups of imino-amino compounds (e.g., 1,2- and 2,3-imino-aminoisoquinolines) can be nicely visualized by consideration of the different aromaticities of the two derivatives (Figure 2).

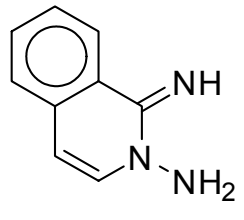

a<smiles>N=c1cc2ccccc2cn1N</smiles>

b

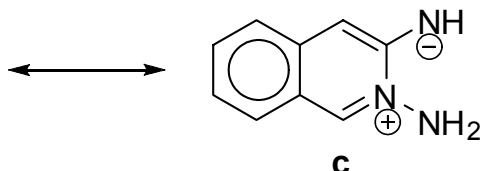

C

\section{Figure 2}

Whereas the aromatic character of the fused benzene ring in the 1,2-substituted derivative a can clearly be demonstrated by the structural formula (circle), the 2,3-isomer b lacks this stabilizing structural moiety, and only its dipolar valence-bond structure can be regarded as a partially aromatic form. This qualitative consideration reveals that the 2,3-isomer should have an electronic distribution which is close to the resonance structure c, i.e., the $C$-imino nitrogen atom has a considerable partial negative charge. It is important to note that in a the basicity of the $N$ amino-nitrogen atom is substantially increased by the adjacent ring-nitrogen atom (manifestation of an $\alpha$-effect ${ }^{9,10}$ ) and thus the higher reactivity of this nitrogen atom compared to the iminonitrogen atom seems obvious.<smiles>N#Cc1c(N)[n+](N)cc2ccccc12</smiles>

3d $\mathrm{MsO}^{\ominus}$

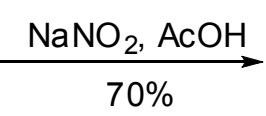<smiles>N#Cc1c(O)ncc2ccccc12</smiles>

14

\section{Scheme 5}

An interesting consequence of this mechanism is the following experimental observation. In 2,3-diamino-4-cyanoisoquinolinium mesylate, 3d, the strongly electron-withdrawing cyanogroup in close vicinity to the C-amino group substantially decreases its basicity, and consequently the two amino groups will have opposite relative basicities. Thus, route $A$ (Figure 1) will take place. Interestingly, in this case, further diazotation also occurs, and 3-hydroxy-4cyanoisoquinoline (14) can be obtained in good yield.

In principle, appropriate modifications (e.g., introduction of electron-donating substituents into suitable positions) in $\mathbf{7 , 1 0}$, and 12 could result in orientation of the pathways to the $B$-route 
and could provide tetrazoles also in these cases. All our efforts in this respect have failed, so far, but further investigations are in progress.

\section{Experimental Section}

General Procedures. Melting Points were determined on a Kofler apparatus and are uncorrected. The IR spectra were recorded on a Thermo Nicolet Avatar 320 FT-IR spectrometer . Experiments were performed on Varian INOVA-200 or Varian INOVA-400 spectrometer equipped with a $5 \mathrm{~mm}$ inverse detection z-gradient probe. ${ }^{1} \mathrm{H}$ and ${ }^{13} \mathrm{C}$ NMR spectra were measured at room temperature $\left(25{ }^{\circ} \mathrm{C}\right)$ in an appropriate solvent. ${ }^{1} \mathrm{H}$ - and ${ }^{13} \mathrm{C}$ - chemical shifts are expressed in ppm $(\delta)$ referenced to residual solvent signals, and ${ }^{15} \mathrm{~N}$-chemical shifts to neat nitromethane. The complete signal assignment was performed by running $2 \mathrm{D}$-heteronuclear $\left({ }^{1} \mathrm{H}-\right.$ ${ }^{13} \mathrm{C}$ and $\left.{ }^{1} \mathrm{H}_{-}{ }^{15} \mathrm{~N}\right)$ gHSQC and gHMQC measurements. The pulse programs were taken from the Varian software library. Elemental analyses were carried out with an Elementar Vario EL III apparatus. Chromatographic separations were carried out on Merck Kieselgel 60 (230-400 mesh). Reactions were monitored with Merck Kieselgel 60 F254-precoated TLC plates (0.25 mm thickness). All the chemicals and solvents were used as supplied. All derivatives unless discussed below have been prepared according to earlier published procedures.

\section{General procedure for reaction of 2,3-diamino-isoquinolinium salts with nitrous acid}

A solution of the appropriate 2,3-diamino-isoquinolinium salt $(3 \mathrm{mmol})$ in a mixture of $10 \mathrm{~mL}$ of acetic acid and $10 \mathrm{~mL}$ of water was treated with a solution of $0.35 \mathrm{~g}(5.1 \mathrm{mmol})$ sodium nitrite in $3 \mathrm{~mL}$ of water at room temperature for $1 \mathrm{~h}$. Crystalline precipitate was formed which was filtered off and recrystallized from acetonitrile.

Formation of the mixture of 10-benzyltetrazolo[1,5-b]isoquinoline (4c) and 3-azido-4benzylisoquinoline (5c). This was obtained by starting from 2,3-diamino-4benzylisoquinolinium 4-methylbenzenesulfonate $(1.26 \mathrm{~g}, 3 \mathrm{mmol})$, to give yellow crystals: 0.43 g (55\%), mp: $130-132^{\circ} \mathrm{C}$. IR ( $\left.\mathrm{KBr}, \mathrm{cm}^{-1}\right): 3061,2130,1600,1495,1454,1395,100 .{ }^{1} \mathrm{H}-$ and ${ }^{13} \mathrm{C}$-NMR data are summarized in Table 3 . From the ratio of the azide and tetrazole chemical shifts, the DMSO solutions contain 85\% tetrazole ring chain tautomers. Anal. Calcd for $\mathrm{C}_{16} \mathrm{H}_{12} \mathrm{~N}_{4}$ (260.29): C, 73.83; H, 4.65; N, 21.52. Found: C, 73.55; H, 4.42; N, 21.40.

3-Hydroxyisoquinoline-4-carbonitrile (7). Starting from 2,3-diamino-4-cyano-isoquinolinium 2,4,6-trimethylbenzenesulfonate (3c, $1.15 \mathrm{~g}, 3 \mathrm{mmol})$; yellow crystals, $0.36 \mathrm{~g}$ (70\%), mp $>300^{\circ} \mathrm{C}$. IR $\left(\mathrm{KBr}, \mathrm{cm}^{-1}\right): 3061,2670,2216,1645,1558,1469,13999,1224 .{ }^{1} \mathrm{H}$ NMR $\delta\left(\mathrm{CDCl}_{3}+\mathrm{DMSO}_{6}\right): 13.3$ (br, $\left.1 \mathrm{H}, \mathrm{H}-\mathrm{OH}\right), 8.82$ (s, $\left.1 \mathrm{H}, \mathrm{H}_{1}\right), 7.82$ (d., $\left.1 \mathrm{H}, J=8.5 \mathrm{~Hz}, \mathrm{H}_{8}\right), 7.68$ and $7.62\left(\mathrm{~m}, 2 \mathrm{H}, \mathrm{H}_{5}, \mathrm{H}_{6}\right), 7.20\left(\mathrm{~m}, 1 \mathrm{H}, \mathrm{H}_{7}\right) .{ }^{13} \mathrm{C} \mathrm{NMR} \delta\left(\mathrm{CDCl}_{3}+\mathrm{DMSO}-d_{6}\right): 85.6,114.6,118.6$, 120.6, 122.5, 128.4, 133.3, 140.1, 150.1, 160.8. Anal. Calcd for $\mathrm{C}_{10} \mathrm{H}_{6} \mathrm{~N}_{2} \mathrm{O}$ (170.17): $\mathrm{C}, 70.58 ; \mathrm{H}$, 3.55; N, 16.46. Found: C, 70.21; H, 3.38; N, 16.36 . 
Reaction of 1,2-diaminopyridinium tosylate (7) with nitrous acid. Application of the general procedure led to formation of a suspension, from which the solid was filtered off to give $2-1 \mathrm{H}-$ pyridone $(9,1.0 \mathrm{~g}, 1.05 \mathrm{mmol}, 35 \%)$. The mother liquor was then extracted several times with dichloromethane, and evaporation of the organic solvent and recrystallization of the residue from hexane yielded the 2-aminopyridine $8(0.85 \mathrm{~g}, 0.9 \mathrm{mmol}, 30 \%)$. All physical data (mp, IR and ${ }^{1} \mathrm{H}-\mathrm{NMR}$ ) of $\mathbf{8}$ and $\mathbf{9}$ were found to be identical with those of the authentic samples)

Reactions of 1,2-diamino-isoquinolinium tosylate (10), and 1,2-diaminoquinolinium tosylate (12) with nitrous acid. Application of the general procedure resulted in the formation of clear solutions, from which the products - 1-amino-isoquinoline (11, $2.24 \mathrm{~g}, 1.56 \mathrm{mmol}, 52 \%)$ and 2aminoquinoline $(\mathbf{1 2}, 2.07 \mathrm{~g}, 1.44 \mathrm{mmol}, 48 \%)$, respectively - were isolated by extraction and recrystallization from ethanol. All physical data (mp, IR and ${ }^{1} \mathrm{H}-\mathrm{NMR}$ ) of $\mathbf{1 0}$ and $\mathbf{1 2}$ were found to be identical with those of the authentic samples)

\section{Acknowledgements}

Financial supports GVOP-3.2.1-2004-04-0311/3.0 and GVOP-3.2.1-2004-04-0210/3.0 are cordially acknowledged.

\section{References and Notes}

1. Filák, L.; Riedl, Zs.; Egyed, O.; Czugler, M.; Hoang, C. H.; Schantl, J. G.; Hajós, Gy. Tetrahedron 2008, 64, 1101.

2. Messmer, A.; Hajós, Gy. J. Org. Chem. 1981 46, 843.

3. Messmer, A.; Hajós, Gy. J. Heterocyclic Chem. 1976, 13, 881.

4. Hajós, Gy.; Riedl, Zs. In Comprehensive Heterocyclic Chemistry III, Cossy, J., Ed.; Elsevier: Amsterdam, 2008, Vol. 11, p 645,

5. Cmoch, P.; Wiench, J. W.; Stefaniak, L.; Webb, G. A. J. Mol. Struct. 1999, 510, 165.

6. Kanyalkar, M.; Coutinho, E. C. Tetrahedron 2000, 56, 8775.

7. Itoh, T.; Miyazaki, M.; Maeta, H.; Matsuya, Y.; Nagata, K.; Ohsawa, A. Bioorg. Med. Chem. 2000, 8, 1983.

8. Heravi, M. M.; Sadjadi, S.; Hekmatshoar, R.; Oskooie, H. A.; Bamoharram, F. F. Monatshefte 2008, 139, 107.

9. Fleming, I. Frontier Orbitals and Organic Chemical Reactions, Wiley: London, 1976; p 77.

10. Hudson, R. F. Angew. Chem. Int. Ed. 1973, 12, 36. 